\title{
LUHMANN COMO INTÉRPRETE DE HUSSERL: EL PROBLEMA DEL SENTIDO
}

\author{
Lionel Lewkow ${ }^{1}$ \\ Universidad de Buenos Aires - CONICET
}

http://dx.doi.org/10.5209/rev_NOMA.2012.v34.n2.40738

\begin{abstract}
Resumen.- Una interpretación frecuente de la relación entre la teoría de sistemas sociales de Niklas Luhmann y la fenomenología de Edmund Husserl sostiene que los conceptos de sentido de ambos autores son cercanos. Esta lectura ha sido elaborada por algunos comentaristas e impulsada enfáticamente por el mismo Luhmann. El propósito de nuestro artículo es revisar críticamente esta interpretación. Sostenemos que la perspectiva fenomenológica y la sistémica se separan en puntos centrales en lo que respecta al tema del sentido. En lo que sigue mostraremos cómo el sociólogo generalizó hacia el ámbito de los sistemas sociales y psíquicos conceptos que Husserl elaboró para alumbrar la conciencia. Por otra parte, señalaremos que mientras Luhmann enfocó la cuestión del sentido en el marco de una perspectiva funcionalista y empírica, Husserl expuso este problema describiendo las estructuras esenciales de la subjetividad trascendental. Asimismo, se evidenciará que el concepto de sentido de Luhmann hace énfasis en la autorreferencia de los sistemas psíquicos y sociales, mientras que el de Husserl se concentra en la heterorreferencia de la conciencia. Como parte de este recorrido, propondremos que, en cuanto el sociólogo interpretó las nociones de horizonte y mundo, según los conceptos de complejidad y contingencia, se alejó de la fenomenología. En compendio, estos aspectos nos llevarán a señalar que entre una y otra perspectiva prevalecen las divergencias antes que las convergencias. Señalaremos como puntos de encuentro entre Luhmann y Husserl a la diferenciación del sentido y el lenguaje y la consideración del mundo como unidad de un horizonte que no se puede equiparar a una mera suma de cosas.
\end{abstract}

Palabras clave.- Luhmann; Husserl; Sentido

\begin{abstract}
A common interpretation of the relation between Niklas Luhmann's theory of social systems and Edmund Husserl's phenomenology maintains that the concepts of meaning of both authors are close to each other. This reading was elaborated by some commentators and emphatically encouraged by Luhmann himself. The aim of our paper is to examine critically such an interpretation. We argue that phenomenological and systemic perspectives do not really match regarding the concept of meaning. What follows will show how the sociologist generalized concepts in social and psychic systems, which Husserl elaborated in order to shed light on consciousness. On the other hand, we will point out that while Luhmann focused on the matter of meaning from a functionalist and empirical perspective, Husserl showed this issue by describing the essential structures of transcendental subjectivity. Equally, we will hold that while Luhmann's concept of meaning has to do with self-reference of psychic and social systems, Husserl's theory stresses hetero-reference of consciousness. Throughout this paper we will state that every time the sociologist interpreted the notions of horizon and world according to the concepts of complexity and contingency, he surely moved away from phenomenology. These aspects lead us to point out that between one and another perspective in reference to meaning, disagreements prevail over affinities. The differentiation of language and meaning and the approach to the concept of world as a horizon unity, which cannot be reduced to a mere addition of things, are shown as convergences between both authors.
\end{abstract}

Keywords.- Luhmann; Husserl; Meaning

\section{Introducción}

\footnotetext{
${ }^{1}$ Doctor en Ciencias Sociales por la Universidad de Buenos Aires y Becario Postdoctoral del CONICET. llewkow@yahoo.com.ar
} 
En el marco de la teoría sociológica, la obra de Niklas Luhmann es considerada como heredera de la perspectiva de sistemas sociales de Talcott Parsons. También es reconocido Luhmann por la renovación que hizo de la teoría sociológica de sistemas al incorporar el concepto de autopoiesis de Humberto Maturana y Francisco Varela. Incluso así, el autor sostuvo que entre los aspectos que anudan su biografía se destaca "...naturalmente la dedicación a Parsons y a Husserl..." (Luhmann, 1987a: 134, nuestra traducción). Por este motivo, advierte Rudolf Stichweh que “...Luhmann, quien tenía una fuerte tendencia a relativizar la relevancia de personas y nombres y a no darle mucho peso en las reconstrucciones intelectuales a las personas (...), hizo dos excepciones. Husserl y Parsons fueron los únicos autores sobre los cuales algunas veces ofreció conferencias... (2010: 7, nuestra traducción).

Además de los escritos que Luhmann consagró a la fenomenología, ${ }^{2}$ la cantidad de referencias a Husserl que pueden encontrarse en los textos del autor confirman el lugar destacado que el filósofo tuvo para su enfoque.

A propósito, algunos comentaristas señalan que el concepto de sentido de Luhmann es cercano al de Husserl. Ejemplo de ello es el glosario sobre la teoría de sistemas sociales que elaboraron Corsi, Esposito y Baraldi, donde se lee que "Basándose en la fenomenología de Edmund Husserl, Luhmann afirma que el sentido es la premisa para la elaboración de toda experiencia (...): se presenta como excedente de referencias de un dato experimentado a ulteriores posibilidades de experimentar (...). Esta definición fenomenológica puede inscribirse en una teoría de los sistemas, en la cual el concepto de sentido se vuelve fundamental" (Corsi, et al., 1996: 14).

Enfáticamente fue favorecida esta lectura por Luhmann mismo, quien, al respecto, sostuvo que "...las disposiciones de Husserl sobre la teoría del sentido pueden integrarse textualmente a la teoría de sistemas en la sociología" (1992a: 241).

El objetivo de nuestro artículo es hacer una revisión de este planteo que asemeja a la teoría de sistemas y la fenomenología. De esta manera, mostraremos los puntos específicos de contacto y distancia entre ambas perspectivas en lo que hace al tema del sentido.

A tales efectos, pondremos en evidencia que la teoría de Luhmann propuso un concepto de sentido que generaliza hacia el ámbito de los sistemas sociales y psíquicos aspectos que Husserl desarrolló para el terreno de la conciencia. Así, si Luhmann enfocó la problemática del sentido desde un punto de vista funcionalista y empírico, Husserl lo hizo describiendo las estructuras esenciales de la subjetividad trascendental. Nuestro recorrido fundamentará, a la vez, que, mientras el enfoque de Luhmann sobre el sentido enfatizó en la autorreferencia de los sistemas sociales y psíquicos, Husserl puso el acento en la heterorreferencia de la conciencia. Por otra parte, argumentaremos que si bien Luhmann retomó las nociones de horizonte y mundo de la fenomenología, las

\footnotetext{
2 Nos referimos al artículo "Die Lebenswelt - nach Rücksprache mit Phänomenologen" (Luhmann, 1986a) y la conferencia "Die neutzeitlichen Wissenschaften und die Phänomenologie" (Luhmann, 1996).
} 
interpretó de acuerdo a los conceptos de complejidad y contingencia, con lo cual se alejó del planteo de Husserl. Estos elementos nos llevarán a sostener que entre el concepto de sentido de una y otra perspectiva priman las divergencias antes que las convergencias. No obstante, señalaremos como puntos de coincidencia a la diferenciación entre sentido y lenguaje, por un lado, y al concepto de mundo como horizonte último no equiparable a una mera suma de objetos, por otro.

A fin de dar solvencia a este planteo, comenzaremos presentando algunos de los aspectos principales del concepto de sentido de Luhmann y cómo éste se apoya en la filosofía de Husserl. Seguidamente revisamos los escritos de Husserl para desarrollar los tópicos de la fenomenología que fueron mencionados por el sociólogo. Cerramos el texto con un balance crítico del nexo Luhmann-Husserl.

\section{1. ¿Una "descripción fenomenológica" del sentido?}

Bosquejando la noción de sentido, Luhmann le confirió a la teoría general de sistemas una tonalidad apropiada a las ciencias sociales tratando de evitar objeciones que podrían hacérsele a partir del llamado "Methodenstreit". Por tanto, desarrolló su teoría en un cruce interdisciplinar pero sin desatender la peculiaridad del ámbito de estudio de la sociología.

Para elaborar este enfoque, Luhmann recuperó críticamente la perspectiva de Husserl. Así, en diversas ocasiones, el sociólogo aludió a su propio planteo como una "descripción fenomenológica" del sentido (Luhmann, 1971: 31; Luhmann, 1984: 93). Ahora bien, ¿en qué consiste esta descripción desde el punto de vista de la Systemtheorie?

Detallaremos a continuación algunos elementos del concepto de sentido del autor para señalar los hilos conductores de nuestro contrapunto con la perspectiva de Husserl. ${ }^{3}$

En este terreno, una apuesta central del planteo luhmanniano fue evitar la amalgama entre sentido y subjetividad. El sujeto no tiene ningún privilegio en la constitución del sentido. Por el contrario, los sistemas sociales son sistemas constitutivos de sentido, al igual que los sistemas psíquicos. Ambos tipos de sistemas elaboran sentido de manera autónoma, sin ser investido ninguno de ellos con el carácter de fundamento ulterior del mismo.

La revisión de la vinculación entre sentido y subjetividad conlleva una crítica a la fenomenología. Así, se señala en "Sinn als Grundbegriff der Soziologie" ciertamente, el tratamiento más extenso de Luhmann sobre el tema del sentido- que este concepto ha sido preparado por "...los esfuerzos esclarecedores de la metafísica subjetiva trascendental, ante todo, por su teoría del conocimiento" (1971: 26, nuestra traducción). A ello se añade que "La

\footnotetext{
${ }^{3}$ El presente artículo no enfocará el tema de las "dimensiones del sentido" temporal, social y objetiva (Luhmann, 1971; 1984). Nuestro propósito es delinear los rasgos más generales del concepto de sentido de la teoría de sistemas sociales.
} 
tradición trascendental había sugerido buscar la aclaración del concepto de sentido en referencia al sujeto y definir el sentido por medio de la intención subjetiva" (ibid.). ${ }^{4}$ A partir de ahí, el autor removió a la subjetividad de su puesto, cediendo al sentido el sitio en vacancia. En lo relativo a este enfoque, Luhmann propuso que "...no está impugnada una relación del sentido y la conciencia, su elucidación tiene que señalarse de manera invertida. El concepto de sentido es primario, tiene que definirse sin relación con la noción de sujeto..." (ibid.: 28).

El planteo del Hauptwerk de Luhmann, Soziale Systeme, expresa con claridad el corrimiento del autor respecto a Husserl. Del siguiente modo expuso el sociólogo en qué consiste su "descripción fenomenológica" del sentido: "El lenguaje de esta descripción sugiere una referencia sistémica psíquica. De ella puede y debe, sin embargo, ser abstraída. Husserl había abstraído en dirección a una teoría del sujeto trascendental. Nosotros abstraemos en dirección hacia la validez extendida [de la descripción fenomenológica] para los sistemas personales y para los sociales. Es decir: conceptos como intención, remisión, expectativa, el vivenciar, el actuar, indican (...) elementos, y/o estructuras, que pueden ser adjudicados tanto a los sistemas psíquicos como también a los sociales. La terminología no nos fija todavía pues -en este nivel de la formación teórica- a una de estas referencias sistémicas con exclusión de la otra" (Luhmann, 1984: 93, nuestra traducción). Entonces, el concepto que estamos problematizando fue aplicado por Luhmann a dos instancias constitutivas de sentido autónomas entre sí, es decir, sistemas psíquicos y sistemas sociales. Esta autonomía implica que en la teoría de los sistemas sociales no sólo queda disputada la vinculación entre la subjetividad y el sentido, sino también la pertinencia teórica de la noción de intersubjetividad.

De acuerdo con Luhmann (1986b), el "inter" y el "sujeto" de la intersubjetividad son opuestos porque no se puede dar cuenta del carácter emergente de lo social desde la subjetividad $\mathrm{y}$, mediante la intersubjetividad, es disuelta, igualmente, la autonomía de la conciencia. Por tanto, sostuvo el autor que "Se le ha reclamado a Husserl, a pesar de todos los esfuerzos en la « $V$. Cartesianische Meditation», no haber resuelto el problema de la intersubjetividad ¡Naturalmente, no! Husserl era un pensador muy estricto como para no ver las dificultades en las cuales había incursionado con la posición de un subjetivismo trascendental" (Luhmann, 1986b: 163, nuestra traducción). Aunque el sociólogo reconoció a Husserl la seriedad de haber explicitado las dificultades de su propio planteo, criticó a la noción de intersubjetividad en su fecundidad para echar luz sobre la autonomía y emergencia de lo social. De esta manera, Luhmann optó por tomar como punto de partida de su sociología a un concepto de comunicación fundado en la perspectiva de sistemas autopoiéticos. Con esto, los sistemas psíquicos quedan emplazados en el entorno de los sistemas sociales.

El énfasis en la autonomía de la conciencia y lo social evidencia el vuelco que el autor le dio al tema del sentido respecto a la fenomenología y las nociones de sujeto e intersubjetividad.

\footnotetext{
${ }^{4}$ Como se verá en la siguiente sección, el tema del sentido es elaborado en la fenomenología a partir de la "intención", ante bien, la "intencionalidad" del sujeto.
} 
Otro rasgo destacado de la perspectiva sistémica acerca del sentido es su imbricación con un planteo metodológico funcionalista. Como se mencionó con anterioridad, la perspectiva de Luhmann propone el desmantelamiento de la afirmación de un fundamento del sentido y el mundo. Este punto de vista se expresa en la versión del funcionalismo que delineó el autor.

Por cierto, Luhmann bosquejó su método funcionalista en los 60'. A tales efectos, es medular el encuentro con Parsons en 1960-61. Sin embargo, con anterioridad a este encuentro, las lecturas de Luhmann, en paralelo con el interés por el funcionalismo clásico de la antropología, se enfocaron en Husserl y el cartesianismo, es decir, la puerta de entrada de toda fenomenología. A propósito, recuerda el autor: "En aquel tiempo he leído, ante todo, Descartes y Husserl” (Luhmann, 1987a: 132, nuestra traducción).

Hete aquí un indicio de que el planteo metodológico de Luhmann discutió también con Husserl y no sólo con el funcionalismo parsoniano. Con respecto al sociólogo norteamericano, el problema de referencia del funcionalismo no será ya, entonces, el mantenimiento de una estructura, sino la resolución de problemas de complejidad mediante alternativas estructurales. Se trata de una inversión de los términos "función" y "estructura". A partir de ahí, Luhmann (1967a: 144) propuso, en vez de un estructural-funcionalismo, un funcionalismo-estructural. Esto implica dinamizar la perspectiva funcionalista, la cual, así considerada, expone toda estructura como aleatoria, intercambiable, en otros términos, "equivalente funcional" respecto a problemas de complejidad. El punto de despegue del funcionalismo luhmanniano es la complejidad máxima del mundo, frente a la cual las estructuras de los sistemas sociales ofrecen una complejidad reducida. El funcionalismo de Luhmann es un método comparativo que describe cómo diversos sistemas reducen complejidad. $^{5}$

\footnotetext{
${ }^{5}$ Digamos algunas palabras sobre el concepto de complejidad del autor, ciertamente, un concepto de múltiples aristas. A propósito, en su teoría el horizonte máximo de complejidad es el mundo (Luhmann, 2009a: 265). A partir de ahí, mediante la diferencia entre sistema y entorno, se establecen islas de menor complejidad. Esto llevó a Luhmann a hablar de un "gradiente de complejidad" en la diferencia sistema/entorno (ibid.: 264). No obstante, el aspecto principal del concepto luhmanniano de complejidad es la diferencia elemento/relación, diferencia que, a su vez, constituye el núcleo de su teoría de sistemas autopoiéticos. Desde este punto de vista, el aumento cuantitativo de elementos de un sistema trae aparejado el aumento del número de relaciones posibles entre ellos hasta una extensión no abarcable por el sistema. Por eso, la complejidad requiere la selección de patrones de relaciones, es decir, estructuras y, simultáneamente, la selección de las relaciones en su acaecer efectivo. No obstante, no se trata de un concepto meramente cuantitativo de complejidad. La selección de un elemento para determinadas relaciones, le otorga cualidad a un elemento, pues, todo elemento, es elemento de un sistema. Un último aspecto que se puede mencionar de este enfoque de la complejidad es que no parte de la diferencia simple/complejo. Esto supone discutir a las cosmologías pre-modernas la idea de un Dios cuya "simplicidad" es fundamento de la multiplicidad mundana. De esta manera, Luhmann optó por utilizar la diferencia entre relacionamiento "completo" y "selectivo" (2009b: 60). Una conexión integra de elementos es un valor límite. Más allá de este umbral no pueden vincularse todos los elementos de un sistema en un mismo momento y el relacionamiento se vuelve complejo. En todo caso, la complejidad siempre alude a la abundancia de lo posible y la "coacción a seleccionar" (Luhmann, 1984: 47). De ello se deriva otro aspecto destacado de la teoría de sistemas sociales: la contingencia. Contingencia quiere decir "Ser posible también de otro modo" (1984: 47, nuestra traducción),
} 
A propósito, se lee en "Funktionale Methode und Systemtheorie" que "Una comparación no conduce a la reducción del ente a la esencia, como aún Husserl considera sobre la base de la vieja tradición, sino hacia la consolidación del ente en relación con otras posibilidades" (1962: 59, nuestra traducción). Luhmann (ibid.: 67) referenció esta crítica en la planteo husserliano del §. 87 de Erfahrung und Urteil sobre la "intuición de la esencia". La discusión atañe a la definición de la fenomenología como una "ciencia de la esencia" (Husserl, 1913: 6).

Por otra parte, con su funcionalismo, Luhmann también examinó el carácter trascendental del pensamiento de Husserl. Consecuentemente, en el ensayo "Soziologische Aufklärung" sostuvo que el funcionalismo hace uso de una perspectiva trascendental la cual es caracterizada de este modo: "La reflexión trascendental sobre aquello que yo vivencio realmente, no se muestra (...) como camino hacia evidencias últimas aseguradas, sino como una técnica metódica para convertir toda evidencia en problema..." (1967b: 98, nuestra traducción). Asimismo, sostuvo Luhmann que la reflexión trascendental “...esclarece las estructuras más generales del mundo (...), estructuras que no pueden ser imaginadas por fuera del mundo y, al mismo tiempo, esquematizar su complejidad como reducible" (ibid.: 98).

La posición de Luhmann respecto al trascendentalismo se aclara en una alusión al método de Husserl que aparece en Soziale Systeme. Allí señaló el sociólogo que su enfoque busca "...un quiebre de la apariencia de normalidad, (...) renunciar a experiencias y costumbres, en este sentido -no considerada aquí de modo teórico trascendental- (...) una reducción fenomenológica" (Luhmann, 1984: 162, nuestra traducción).

Entonces, el funcionalismo fue considerado por Luhmann como una epojé que pone en cuestión lo dado por sentado, pero, como tal, es contraria al esencialismo y trascendentalismo de la fenomenología. Al igual que otros aspectos de la teoría de sistemas sociales, el funcionalismo es un capítulo temprano de la lucha del sociólogo contra las ontologías, en otros términos, se trata de una crítica a la noción de fundamento. Utilizando una formulación que Luhmann empleó para caracterizar su concepto de complejidad, se puede decir que la noción de sentido que propuso es deliberadamente "sin fundamento" [haltlos] (Luhmann, 2009b).

En este terreno, el autor sostuvo que la función del sentido es "...posibilitar al mismo tiempo la reducción y conservación de la complejidad..." (Luhmann, 1971: 34, nuestra traducción). Los sistemas sociales y psíquicos enfrentan la complejidad mediante la diferencia entre actualidad y horizonte de potencialidad, diferencia que constituye lo central del concepto de sentido de Luhmann (1971: 32; 1984: 93).

A propósito, Soziale Systeme detalla cómo el autor enfocó el concepto de horizonte: "El fenómeno del sentido aparece en la forma de un exceso de

"Contingente es todo lo que no es necesario, ni imposible" (1992b: 96, nuestra traducción). Lo relevante de este concepto de complejidad para nuestro artículo es, como se verá más adelante, el vínculo entre el exceso de posibilidades y la selectividad, es decir, la contingencia. 
remisiones a posibilidades adicionales del vivenciar y el actuar. Algo está en el foco, en el centro de la intención, y lo otro es insinuado marginalmente como horizonte para un etcétera [Und-so-weiter] del vivenciar y actuar. Todo lo que se intenciona, en esta forma, mantiene abierto el mundo en su totalidad, por lo tanto, garantiza siempre también la actualidad del mundo en la forma de la accesibilidad" (Luhmann, 1984: 93, nuestra traducción).

Dando cuenta de la abundancia de lo posible, el concepto de horizonte alude al tema de la complejidad. Asimismo, refiere al problema de la contingencia. Pues según Luhmann el abanico del horizonte de potencialidad de sentido "....incluye no sólo lo real (o sea, presuntamente real), sino también lo posible (condicionalmente real) y lo negativo (irreal, imposible)" (ibid.: 93). Así, el sentido supone la apertura a lo otro, es decir, la aleatoriedad y la selección de posibilidades. Como señaló el autor: "Contingencia quiere decir, prácticamente, peligro de decepción..." (Luhmann, 1971: 33, nuestra traducción).

Para formular esta mirada sobre la complejidad y la contingencia, retomando la noción de horizonte, Luhmann (1984: 93) hizo mención de los §§. 27 y 47 de Ideen I y los §§. 7-9 de la "Introducción" de Erfahrung und Urteil. Este último texto es el más citado de Husserl en los escritos de Luhmann.

Así, sostuvo el sociólogo que el horizonte último de sentido es el mundo. Ciertamente, Luhmann dedicó más atención a la revisión del concepto husserliano de mundo que a la cuestión del sentido en sí misma. El artículo "Die Lebenswelt" (Luhmann, 1986) es resultado de esta preocupación. Siguiendo a Lothar Eley: "Luhmann está ligado a la fenomenología trascendental de Husserl, el punto de referencia de la teoría de sistemas es el horizonte de mundo" (1972: 14, nuestra traducción).

Ahora bien, valiéndose de los conceptos de complejidad y contingencia, el autor marcó un contraste frente a la perspectiva de Husserl fundada en el carácter primario de la certeza de mundo. De acuerdo con el ensayo "Soziologie als Theorie sozialer Systeme", "Este diagnóstico fenomenológico de la certeza de mundo deja revelar de manera comprensible que la metafísica ontológica podía partir del ser y preguntar por el ser del ente. Mientras tanto en esta pregunta yacía una interpretación que hoy no podemos aceptar más sin reparos, es decir, la interpretación del ser como exclusión del no-ser y con ello como exclusión de las otras posibilidades" (1967a: 166, nuestra traducción).

Esta crítica al planteo husserliano se puede enfocar ilustrando la perspectiva antropológica -nunca desarrollada explícitamente- que subyace a los primeros textos de Luhmann. Antes que disponer de certezas, el hombre es presentado aquí como alguien que enfrenta problemas nunca resueltos de manera acabada. Así, en referencia al método funcional, señaló Luhmann que "Mucho antes de que al hombre le vino a la mente investigar empíricamente su pensar como proceso de solución de problemas y [consideró] copiarlo mecánicamente, se había entendido, en sentido trascendental, como solucionador de problemas..." (1967c: 44, nuestra traducción). La referencia de Luhmann a Husserl es aquí el §. 21-c de Erfahrung und Urteil sobre las "posibilidades problemáticas" y las "posibilidades abiertas". 
Continuando con el tema de la mundanidad, en la perspectiva de Luhmann el mundo es "acéntrico" y "policontextual". Para cada sistema -ya sea social o psíquico- el mundo es la diferencia entre sistema y entorno que integra en sí misma todas las otras diferencias sistema/entorno. Ninguna de estas diferencias constituye el eje del mundo, se trata de un mundo unitario pero articulado por las diversas perspectivas sistema/entorno.

Esto supone considerar que el mundo tampoco está centrado en la subjetividad como si fuese un "...correlato de la conciencia, como mero ser intencional..." (Luhmann, 1984: 283, nuestra traducción). El autor sustentó esta crítica en el ya mencionado $\S .47$ de Ideen $I$.

Ahora bien, en sintonía con el filósofo, observó Luhmann que “...el mundo es más que la comprensión de las remisiones con sentido como mera suma de todas las posibilidades. No es sólo la suma, es la unidad de estas posibilidades" (ibid.: 106). Por esta razón, "El mundo comprendido originaria y fenomenológicamente está dado como unidad inasible" (ibid.: 283).

Dicho esto, la perspectiva fenomenológica de la mundanidad que más renombre adquirió en las ciencias sociales se encuadra en el concepto de "mundo de la vida". Ahora bien, ¿cómo se posicionó Luhmann en este ámbito? El artículo "Die Lebenswelt" ofrece un acceso a la problematización de este asunto en la teoría de sistemas sociales.

Así, el autor criticó a Husserl la amalgama de dos aspectos que consideraba incompatibles en el concepto de mundo de la vida, a saber: la noción de "suelo", por un lado, y la de "horizonte", por otro. Nuevamente, el texto de referencia es la "Introducción" de Erfahrung und Urteil, otra vez, los §§. 7-9. Siguiendo a Luhmann: "...un horizonte no es ningún suelo. Sobre un horizonte uno no puede pararse. (...) Si el mundo de la vida es un suelo, no es ningún mundo, entonces, ningún mundo de la vida. Sin embargo, si es un horizonte, no puede empleárselo como suelo seguro, tampoco puede ser familiar, porque con cada intento de alcanzarlo vuelve a retirarse; en este caso no es ningún mundo de la vida" (Luhmann, 1986a: 269, nuestra traducción).

Ahora bien, ¿por qué el mundo no puede ser horizonte y suelo a la vez? En la perspectiva del autor no son compatibles ambos términos por la razón de que el mundo en Husserl no es más que un "mero correlato de acto", no aquello donde el acto de la conciencia se puede afianzar. Así, el mundo no sería otra cosa que la "autorreferencia desviada del acto mismo" [umgeleitete Selbstreferenz des Aktes selber] (ibid.: 269-270).

El sociólogo buscó desentramar lo que según su perspectiva es una confusión de suelo y horizonte en el planteo husserliano de la mundanidad. A tales fines, se valió de la figura de un mundo "policontextual" señalando que aspectos como la "familiaridad" y la "certeza" no tienen vigencia para el mundo como tal, sino para perspectivas singulares del mundo, es decir, para contextos específicos, o sea, diferentes sistemas con su respectivo entorno. De esta manera, la teoría de sistemas sociales separa la máxima complejidad del mundo y la complejidad reducida de cada perspectiva sistémica específica: 
"Para el mundo, dicho de otro modo, cada centro de actualidad es también lo no-familiar, inseguro, nuevo, opuesto" (ibid.: 271). Desde este punto de vista, la unidad de suelo y horizonte en Husserl esconde un análisis de la distinción entre "familiar" y "no-familiar" (ibid.: 272).

A partir de esta lectura, Luhmann distinguió el concepto de mundo de la vida y la noción de mundo. Siguiendo al autor, "Como mundo de la vida aparece (...) el mundo, si de modo contextual específico, es representado mediante la diferenciación familiar/no-familiar..." (ibid.: 274). Así, el análisis que elaboró Luhmann acerca del concepto de mundo de la vida concluye señalando que "De forma distinta a lo que Husserl proponía, la cuestión del mundo de la vida no conduce de vuelta, por lo tanto, hacia un fundamento unitario, sino hacia la pregunta por la distinción que constituye el mundo de la vida" (ibid.: 285). Brevemente, se trata de la distinción familiar/no-familiar.

Los conceptos de horizonte y mundo le permitieron a Luhmann tratar el tema del sentido en tanto modo peculiar de procesamiento de la complejidad por parte de los sistemas psíquicos y sociales. Sin embargo, el concepto de sentido no alude sólo a la cuestión de la complejidad. El sentido es el reverso de la autopoiesis de los sistemas psíquicos y sociales. Como sostuvo Luhmann: "La automovilidad de los sucesos de sentido es autopoiesis por excelencia" (1984: 101, nuestra traducción). Dicho de otra manera, el sentido es autorreferencial. Del mismo modo que la reproducción autopoiética de los sistemas sociales conecta comunicaciones con más comunicaciones, el sentido siempre remite al sentido y no a otra cosa.

Un último aspecto que ha de destacarse de la perspectiva de Luhmann es que en su planteo el sentido y el lenguaje son conceptos que no se solapan por completo. En lo que respecta a los sistemas sociales, el autor definió la noción de comunicación tomando por eje al lenguaje, sin embargo, sostuvo que éste consiste en una especialización "secundaria" de los procesos de comunicación (Luhmann, 1971: 43). Para que se realice la comunicación "...el lenguaje no es necesario..." (ibid.). ${ }^{6}$ A su vez, afirmó el autor que, si bien hay un uso de signos lingüísticos en los sistemas psíquicos, el lenguaje no sustituye a las operaciones de estos sistemas (Luhmann, 1984: 369). ${ }^{7}$

\footnotetext{
${ }^{6}$ Luhmann $(1984 ; 1987 b)$ definió el concepto de comunicación como la síntesis de tres selecciones: información, notificación [Mitteilung] y comprensión [Verstehen]. Con el uso del lenguaje se hace imposible negar que hubo comunicación, no obstante, hay comunicación siempre y cuando se realice la síntesis de selecciones que caracteriza a la misma. Prueba de ello es la aplicación que Luhmann (1995) hizo del concepto de comunicación a las artes plásticas, entre otras formas del arte.

7 Luhmann no ha definido con claridad la tipología operativa de la conciencia. Así, propuso diferentes versiones sobre este problema. Pues indicó que los sistemas psíquicos operan mediante "representaciones" (1984), en otra ocasión señalo que esta operación son los "pensamientos" (1987c) o bien las "percepciones" (1992c; 1995). Sin embargo señaló que en base al lenguaje "El sistema psíquico gana (...) algo que se podría llamar capacidad de formación de episodios. Puede diferenciar y descontinuar operaciones" (Luhmann, 1984: 369, subrayado en el original, nuestra traducción). Se insinúa aquí, entonces, que la conciencia consiste en un continuo operativo no-lingüístico, el cual, en base al lenguaje, puede separar elementos discretos.
} 
En resumen, el concepto de sentido desarrollado más arriba se basa en los siguientes tópicos: la crítica a las nociones de subjetividad e intersubjetividad y la extensión del concepto de sentido a sistemas psíquicos y sociales autónomos; el método funcionalista como forma de epojé no esencialista, ni trascendentalista; las nociones de horizonte y mundo como aproximaciones a la complejidad y la contingencia en el marco de la discusión del concepto de mundo de la vida; el sentido como forma de autorreferencia de los sistemas sociales y psíquicos; finalmente, la diferencia entre el sentido y el lenguaje. Dicho esto, ¿hay una "descripción fenomenológica" del sentido en Luhmann? Sólo podremos responder a esta cuestión haciendo referencia al planteo del fundador de la fenomenología.

\section{Volviendo a Husserl}

Nuestra estrategia para la presentación de la perspectiva del filósofo será dejarnos orientar por los puntos señalados en el apartado anterior y los pasajes precisos de textos que Luhmann leyó de Husserl. La exposición que realizaremos de la fenomenología no pretende dar cuenta de forma acaba del planteo de Husserl ni hacer aportes sustantivos a la investigación de su teoría. Como se indicó, el foco del artículo es mostrar las distancias y cercanías entre Luhmann y Husserl en el tratamiento del concepto de sentido.

A propósito, la fenomenología es una filosofía de la subjetividad. Para mostrar cómo entendió Husserl la relación sujeto-sentido es necesario dar cuenta de su método. Esto permitirá esbozar un contraste con el funcionalismo de Luhmann en la última sección de nuestro artículo.

Por cierto, contra perspectivas que tendían a llevar a la filosofía hacia el "irracionalismo", la fenomenología se propuso elaborar una filosofía científica. Ahora bien, no se alude con esto a la cientificidad de las ciencias empíricas. Husserl intentó fundar una cientificidad de nuevo cuño.

En Ideen I se expone el ámbito de la filosofía a partir de un método que si bien consta de un conjunto de pasos, puede delinearse según dos momentos decisivos: el primero, la "reducción eidética" y, el segundo, la "reducción fenomenológica". Introduciremos la cuestión metodológica siguiendo el planteo de esta obra -conocida por Luhmann- porque definió lo central de la fenomenología en este terreno.

Al comienzo de Ideen I se distingue entre "hechos" y "esencias". Husserl aludió con esto a diferentes tipos de ciencias. En contraste con las "ciencias de hechos", la reducción eidética muestra a la fenomenología como una "ciencia de las esencias". De esta manera, señaló el filósofo que la incursión en el conocimiento de las esencias se basa en "La reducción correspondiente que lleva del fenómeno psicológico a la «esencia» pura [de éste]..." (Husserl, 1913: 6, nuestra traducción). Incluso así, Husserl consideró que con la reducción eidética no quedaba todavía alcanzado el ámbito de investigación de su filosofía. Para que esto sea posible se requiere otro paso: la reducción fenomenológica. 
En Ideen I Husserl no buscó simplemente dar cuenta de la conciencia empírica y su relación con los objetos, su fenomenología pretendía cuestionar toda posición de existencia, es decir, el mundo "real" en su totalidad. En efecto, con la reducción eidética, el tema de la existencia de los objetos, su mundanidad y la de la conciencia, quedan aún abiertas. No obstante, como especificó el filósofo, "Nuestra fenomenología debe ser, no una ciencia de fenómenos reales, sino de fenómenos trascendentalmente reducidos..." (ibid.). En consecuencia, el planteo husserliano enfoca la esencia de las vivencias de la conciencia trascendental. La reducción fenomenológica es "trascendental" porque suspende toda creencia ingenua e inmediata en la "realidad", "pone entre paréntesis" la "actitud natural" que asume el hombre en la vida cotidiana. A partir de ahí, Husserl mostró las estructuras esenciales de la relación de la conciencia trascendental con el mundo y sus objetos, los cuales, alumbrados por la fenomenología, no son tenidos en cuenta como "reales", sino en sus modos subjetivos de aparecer, es decir, en tanto "fenómenos".

Entonces, hay que diferenciar, por un lado, el elemento metodológico que distingue hechos y esencias - la reducción eidética- y, por otro, el procedimiento que cuestiona la creencia ingenua en la existencia y reconduce la objetividad íntegra a sus modos subjetivos de aparecer -la reducción fenomenológica-.

Luhmann no hizo ninguna mención precisa al aspecto trascendental del método de Husserl, pero sí especificó su referencia a la cuestión eidética. Como se vio más arriba, la referencia del sociólogo fue el §. 87 de Erfahrung und Urteil. En esta parte del texto póstumo de Husserl quedó delineado el elemento eidético del método de la fenomenología como "libre variación" o, lo que es lo mismo, "variación eidética". El problema se enmarca en un contraste de los conceptos de las ciencias empíricas y los conceptos de la fenomenología, en otras palabras, las "universalidades empíricas" [empirische Allgemeinheiten] y las "universalidades puras" [reine Allgemeinheiten], tema al que aludimos recién con la diferencia entre "ciencias de hechos" y "ciencia de las esencias".

El punto que nos interesa destacar de este contraste es el siguiente: para Husserl las universalidades sustentadas en la "comparación empírica" anticipan casos que se subsumen bajo una generalidad pero esto no se da con una legalidad necesaria. Los conceptos de las ciencias empíricas siempre están sujetos a una posible discordancia. Hay una "accidentalidad" [Zufälligkeit] del concepto de las ciencias empíricas. El punto de partida de la generalización es algo accidental, dado a la experiencia fáctica, y las siguientes igualdades y semejanzas que señala el concepto, son también accidentales, sujetas a eventual reconsideración.

Por el contrario, en el caso de las universalidades puras no está presente esta accidentalidad del concepto empírico, justamente, porque prescriben de antemano la esencia de toda posible situación. De esta manera, en el planteo de Husserl se habla de la "necesidad" [Notwendigkeit] de las universalidades puras o "a priori" (1939: 409-410). 
La variación eidética, sostenemos con Klaus Held, “...explica cómo esta universalidad incondicional del pensamiento llega a estar originalmente dada" (2003a: 16, nuestra traducción). En el §. 87 de Erfahrung und Urteil Husserl sostuvo que el procedimiento de la libre variación, en vez de basarse en la comparación empírica, da lugar a variantes de una objetividad en la fantasía de modo arbitrario. A través de la multiplicidad de variaciones se deja entrever un aspecto invariante como "forma general necesaria", forma que se destaca como el "contenido absolutamente idéntico" del objeto en cuestión. Con esto se evidencia la esencia de un objeto. La "intuición de la esencia" consiste en la aprehensión activa de la mismidad que resulta de las variantes generadas, frente a sus diferencias.

Veamos ahora cómo se define en el planteo husserliano la relación entre subjetividad y sentido, cuestión que, revisada críticamente, fue el punto de despegue del concepto de sentido de Luhmann. Siguiendo el planteo de Ideen I sostuvimos que la fenomenología estudia las estructuras esenciales de la relación de la conciencia trascendental con el mundo y sus objetos los cuales son entendidos como fenómenos.

Es en el marco de esta relación -el tradicional y problemático vínculo sujetoobjeto- donde tiene que exponerse el concepto fenomenológico de sentido. Para desarrollar este tema hay que dar cuenta de la noción vertebral de la fenomenología, a saber: la de intencionalidad.

Ciertamente, Husserl heredó este concepto de su mentor filosófico, Franz Brentano, quien, a su vez, lo había retomado de la escolástica. La noción de intencionalidad le permitió al fenomenólogo mostrar la unidad de sujeto y objeto, como fue de su filosofía tal propósito.

Basaremos nuestra exposición de esta cuestión, nuevamente, en Ideen I donde se muestra en detalle la estructura de la intencionalidad. Al respecto, Husserl sostuvo que "La intencionalidad es lo que caracteriza a la conciencia en sentido preciso..." (1913: 187, nuestra traducción). Así, las vivencias de la conciencia quedan definidas por su condición de "ser conciencia de algo" (ibid.: 188). La intencionalidad alude a la orientación de la conciencia hacia un objeto. La conciencia, en todas sus formas, ha de vérselas con objetos. Dicho con una terminología familiar al planteo de Luhmann, la conciencia es "heterorreferencial". Por tanto, no es posible pensar una conciencia vacía, carente de un objeto. En cuanto tal objeto no es necesariamente empírico también la fantasía, por ejemplo, tiene un objeto fantaseado-, la intencionalidad constituye un carácter esencial de la conciencia. De esta manera, puede hablarse de un "a priori de la correlación" de la conciencia y su objeto.

Ahora bien, el planteo fenomenológico postula que hay vivencias que no llevan la impronta de la intencionalidad. Pues hay que oponer a la "vivencia intencional", las "vivencias en sentido más amplio" (ibid.: 73-74). Dicho de otra manera, "... no todo momento real [reelles Moment] en la unidad concreta de 
una vivencia intencional tiene el carácter fundamental de la intencionalidad, por tanto, la propiedad de «ser conciencia de algo»" (ibid.: 74). ${ }^{8}$

En este terreno, sostuvo Husserl que hay dos tipos de vivencias articuladas en la unidad de la vivencia concreta: vivencias intencionales y no-intencionales. Mientras que las vivencias no-intencionales son las sensaciones, de modo más preciso, los "datos hyléticos"; las vivencias intencionales son las formas, o "noesis", encargadas de "dar sentido" [Sinngebung] a las sensaciones.

A propósito de ello, caracterizamos a la intencionalidad como "conciencia de algo". Igualmente, se dijo que en la perspectiva de Husserl la conciencia tiene un carácter orientado, está direccionada a un objeto, en otras palabras, tiene un "correlato intencional". Lo que investiga la fenomenología es la "correlación" esencial entre los objetos y sus maneras subjetivas de darse. El autor empleó el concepto de "noema" para dar cuenta del objeto en el marco de la estructura de la intencionalidad y propuso que éste es resultado de la síntesis de los datos hyléticos y la noesis. Precisamente, el sentido es un aspecto del objeto en el marco de la intencionalidad. Veámoslo en detalle.

Respecto al objeto intencional hay que decir que, en contraste con la noesis y los datos sensibles, si bien es "dependiente" [unselbständig] de las vivencias, las trasciende. Como sostuvo Husserl, su filosofía expone “...una esfera absoluta de materias y formas noéticas (...), a cuyos entrelazamientos de modos determinados con necesidad esencial inmanente pertenece este maravilloso tener consciente algo determinado o determinable, dado de tal y cual manera, que es algo que está enfrente [ein Gegenüber] a la conciencia misma, en principio otro, irreal [irreell], trascendente... (ibid.: 228, nuestra traducción, subrayado en el original). ${ }^{9}$

Ahora bien, aunque el correlato intencional no forma parte de las vivencias, siendo dependiente de estas, tampoco alude el concepto de noema al objeto empírico. Las consideraciones de Husserl se mueven en el terreno de la "desconexión" o "puesta entre paréntesis" del mundo "real", ámbito en el cual describió al noema en correlación con la noesis. ${ }^{10}$

\footnotetext{
${ }^{8}$ El término "momento real" alude a la participación de las vivencias en la temporalidad de la conciencia. No ha de confundirse este sentido de "real" [reel] con lo "real" [wircklich] como "realidad" [Wirklichkeit] de un objeto empírico.

9 "Irreal" [irreel/] -por contraste al ya mencionado "momento real" de la conciencia- quiere decir aquello no temporalizado en la misma. De ahí el carácter "ideal" del objeto intencional que se mantiene idéntico a través de los cambios de las vivencias de la conciencia.

${ }^{10}$ Antes se comentó que incluso la fantasía tiene un objeto y, por eso, el objeto intencional no es necesariamente empírico. Ahora se puede dar precisión a esta constatación. El noema se distingue "esencialmente" de los objetos en su efectividad (primer momento del método de Husserl: la distinción entre hechos y esencias, es decir, la reducción eidética) y "trascendentalmente" de los objetos mundanos (segundo momento del método: la distinción entre la esfera trascendental y la mundana, o sea, la reducción fenomenológica). Con el ejemplo de la percepción de un objeto externo, el autor expuso claramente lo que estamos señalando: "El árbol simplemente puede quemarse, desintegrarse en sus elementos, etc. Pero el sentido -el sentido de esta percepción, necesariamente perteneciente a su esencia- no puede incendiarse, no tiene elementos químicos, ninguna fortaleza, ningunas propiedades reales" (1913: 205, nuestra traducción). El sentido no se confunde con los aspectos empíricos y mundanos del objeto percibido.
} 
En este marco, la fenomenología considera al sentido como el "estrato-núcleo" [Kernschicht] del noema. Por eso se puede hablar de "sentido noemático" o "sentido objetivo" (ibid.: 206). A propósito, hay dos aspectos del noema: en primer lugar, el "objeto puro y simple" [Gegenstand schlechthin], al que también llamó Husserl "X determinable" [bestimmbare X] (ibid.: 301). Se trata del objeto intencional "idéntico" como "punto de unidad" o "soporte" de las predicaciones posibles. Es un mero "esto", algo indefinido. En segundo lugar, refirió el filósofo al "objeto en el cómo de sus determinaciones" [Gegenstand im Wie seiner Bestimmtheiten] (ibid.: 301-303). El sentido no es el mero objeto abstracto e indeterminado, "El «sentido» (...) es este noemático «objeto en el cómo»" (ibid.: 303).

Recapitulando, en Ideen I el sentido se define como el estrato-núcleo del noema compuesto por un centro de unidad con sus determinaciones. Este núcleo del correlato objetivo de la conciencia resulta de la amalgama de la noesis con los datos hyléticos. Así, en el lado noético de la intencionalidad se puede aludir al "dar sentido", y en lado noemático, al "sentido". Expresado de una manera más sencilla, quedan aquí delineados los dos aspectos básicos del planteo de Husserl basado en la intencionalidad cuyo fin no fue otro que considerar de manera monista sujeto y objeto: el sentido es el núcleo del objeto intencional y supone una subjetividad "heterorreferente" que confiere sentido.

Dicho esto, hay que distinguir entre el sentido y la "significación" [Bedeutung] (Husserl, 1913: 284-288). Mientras el sentido cubre la totalidad del terreno de la correlación noético-noemática, la significación abarca un ámbito circunspecto. Se trata de la esfera de las expresiones del lenguaje. Con esto, si de manera amplia mencionamos el "sentido" noemático y el "dar sentido" noético, acá se requiere hacer referencia a la "significación" y el "significar" [Bedeuten] (ibid.: 285). Para que haya sentido no se precisa ni la "enunciación" [Wortlaut], ni el "significar de la palabra" [Wortbedeuten] (ibid.). La "expresión" [Ausdruck] entendida como expresión lingüística-, "...es una forma singular, que se puede adaptar a todo «sentido» (el «núcleo» noemático)..." (ibid.: 286).

Como resultado de estas observaciones se subraya la necesidad de distinguir el nivel de análisis del sentido y el de la significación, es decir, el lenguaje. Pues Husserl propuso que hay sentido no lingüístico.

Antes de desarrollar el concepto de horizonte y, por tanto, la noción fenomenológica de mundo, es necesario especificar el concepto de "protodoxa" [Urdoxa]. En este terreno, Husserl distinguió los "caracteres de creencia" y los "caracteres de ser" (ibid.: 238). También aquí la distinción tiene que ver con la separación entre las vivencias y lo que, siendo consciente en ellas, las trasciende, es decir, el objeto intencional.

Por tanto, hay variados modos de creencia que pueden explicitarse en la noesis y, correlativamente, otros tantos modos de ser del noema. Esto mismo fue señalado por Husserl aludiendo a los actos "ponentes" del ser [Seins"setzende" Akte] o actos "téticos" ["tetische" Akte] en los cuales el objeto intencional queda determinado conforme a diferentes modalidades: "...en todo momento y necesariamente un núcleo noemático es consciente, un «noema de 
un objeto», que tiene que ser caracterizado de alguna manera..." (ibid.: 238). En suma, el tema de los modos de creencia y de ser o, lo que es lo mismo, la "tesis" que en cada caso recubre al sentido noemático, añade otro elemento para investigaciones por sendas vías noéticas y noemáticas de la intencionalidad.

Así, afirmó Husserl que hay una "forma primitiva de los modos de creencia" [Urform der Glaubensweise] y, paralelamente, una "forma primitiva de todas las modalidades de ser" [Urform aller Seinsmodalitäten] (ibid.: 240). Se trata de la "certeza de creencia" [Glaubensgewißheit] y el "ser «cierto» o «real»" ["gewi $\beta$ " oder "wirklich" seiend] como carácter de ser vinculado a ella. Entonces, el lado noemático de la intencionalidad está determinado como "realidad" [Wirklichkeit], la cual es consciente, del lado noético, en la forma de la "certeza".

En este terreno, el filósofo consideró a esta certeza como "no-modificada" o "no-modalizada" (ibid.: 240). Por tales razones la denominó "proto-doxa" (ibid.: 241). Es la creencia primaria en la que se apoyan otros modos de creencia y de ser en tanto "modificaciones" de la misma. La proto-doxa es la forma primaria en que es investido el sentido, a saber: como "realidad" tenida por "cierta".

Pasemos ahora al tema central en el vínculo Luhmann-Husserl en lo que hace a la problemática del sentido, a saber: la diferencia actualidad/potencialidad.

En la mirada fenomenológica, la idea de potencialidad está encuadrada en el concepto de "horizonte". Al respecto, en Ideen I Husserl expuso que la conciencia puede apuntar a su objeto de modo actual o inactual: "Una vez la vivencia es, por así decirlo, conciencia «explícita» de su objeto, la otra vez, implícita, meramente potencial" (ibid.: 72). La conciencia potencial del objeto puede pasar a actualidad y, en sentido contrario, lo actual puede transponerse en inactualidad.

Esto es así porque el objeto siempre está dado a la conciencia de manera parcial, a través de "matización" [Abschattung], supone partes no atendidas, es decir, un horizonte de mayor o menor indeterminación (ibid.: 91).

De todos modos, hay un horizonte más amplio en el que los objetos se insertan. En Ideen I este horizonte fue entendido como el "entorno" [Umwelt] de la actitud natural. El entorno es el mundo en el modo inmediato e ingenuo en que los hombres se relacionan con él. Sin embargo, este texto no emprendió una descripción exhaustiva de la actitud natural aunque Husserl manifestó tal tarea es "excepcionalmente importante" (ibid.: 60). Esto pone al descubierto un interés en la temática del mundo que va a adquirir todo su peso con el concepto de Lebenswelt de los escritos tardíos del filósofo.

En esta línea, se afirma en Ideen I que hay una "tesis general de la actitud natural" (ibid.: 60) pero tal concepto no tiene aquí entidad propia, su función es la de ofrecer un contraste a la "actitud fenomenológica" (ibid.: 106). De todas maneras, quedan definidos en este texto algunos trazos del concepto fenomenológico de mundo. 
Pues la "tesis de la actitud natural" no alude a otra cosa que la proto-doxa: en la actitud natural el mundo tiene el carácter de ser de la "realidad" y es consciente para el hombre en el modo de creencia de la "certeza". En relación con esta certidumbre, Husserl explicitó otros rasgos del mundo inmediato.

Como vimos en el apartado anterior, para Luhmann fueron relevantes los §§. 27 y 47 del texto que estamos comentando. Aquí Husserl trabajó el tema de la mundanidad y la actitud natural.

Siguiendo lo desarrollado por el filósofo, se constata que la noesis que constituye la medula de la mundanidad es la percepción. En la percepción los objetos son vislumbrados como objetos "reales", es decir, "cosas corpóreas" [körperliche Dinge] que están "ahí delante" [vorhanden] (ibid.: 56).

Asimismo, el entorno de la actitud natural no es un "mero mundo de cosas" [bloße Sachenwelt], sino un "mundo de valores" [Wertwelt], un "mundo práctico" [praktische Welt] (ibid.: 58). Primariamente, se encuentra el hombre "objetos de uso" [Gebrauchsobjekte] -"...la mesa con sus libros..."- y sus "caracteres de valor" -"bello", "feo", etc.- (ibid.: 58).

Es este un mundo intersubjetivo en el que los otros hombres "...están para mí inmediatamente ahí..." (ibid:: 56). Como se lee en el §. 29, se trata del "...entorno existente, de todos nosotros, al cual nosotros mismos pertenecemos" (ibid:: 60). Precisamente, sostuvo Husserl en su "V. Cartesianische Meditation" que el problema de la intersubjetividad no abarca sólo la cuestión del otro sujeto. Sobre la base de la pregunta por el alter ego hay que fundamentar la constitución de un mundo compartido objetivo, un mundo real "Für-Jedermann-da" (Husserl,1931: 124). Se trata de un planteo acerca de la intersubjetividad en el terreno de la esfera trascendental. De esta manera, si bien el punto de partida de Husserl para dar cuenta del sentido y el mundo fue la subjetividad trascendental, no planteó un solipsismo, el sentido y el mundo se fundan en la intersubjetividad trascendental.

Volviendo a Ideen I, Husserl sostuvo que el "campo de la percepción actual" y un "contorno" [Umgebung] de lo determinado, no agotan el mundo que está ahí delante. El mundo es un horizonte infinito nunca completamente determinable (Husserl, 1913: 57). Precisamente, en el §. 47, también mencionado por Luhmann, el filósofo expuso que la relación entre determinación e indeterminación, actualidad y potencialidad, se rige según "tipos a priori" [apriorische Typen] (ibid.: 102). De esta manera, las "posibilidades de plenificación" [Erfüllungsmöglichkeiten] del horizonte no son arbitrarias, no puede venir cualquier cosa al caso, sino algo predeterminado por su "tipo esencial" [Wesentypus] (ibid.).

Un aspecto que Luhmann puntualizó, aunque no aparece en las partes de Ideen I que él menciona, es que el mundo, de acuerdo con el concepto de intencionalidad que expusimos más arriba, es un correlato de la conciencia. Como señaló Husserl, el mundo tiene su sentido como "mero ser intencional", es decir, un "sentido secundario", el "sentido relativo de un ser para una conciencia", por fuera de ello es "una nada" [ein Nichts] (ibid.: 106). 
De todos modos, el sociólogo no sólo hizo alusión a Ideen I para dar cuenta del tema de la mundanidad, también referenció la problemática en Erfahrung und Urteil. Al igual que Die Krisis, este escrito pone énfasis en la cuestión de la mundanidad entendida como Lebenswelt. La cuestión de la mundanidad desarrollada en Ideen I anticipa esta figura conceptual que aparece en el Husserl tardío.

A diferencia de la óptica de Ideen I, en Die Krisis el problema del mundo de la vida no ofrece un mero contraste para la actitud fenomenológica, tampoco se reduce su tratamiento a un simple intento de fundamentación de las ciencias. La cuestión de la mundanidad subjetivamente constituida, en vez de observarse como un problema parcial, va a ser considerada como el problema filosófico por antonomasia (Husserl, 1936: 135). Es aquel problema que permaneció en el "anonimato" para las ciencias y la filosofía: "Ninguna ciencia objetiva, ninguna psicología que, sin embargo, quisiera ser ciencia universal de lo subjetivo, ninguna filosofía, ha tematizado nunca y, consecuentemente, realmente divisado este reino de lo subjetivo" (ibid.: 114, nuestra traducción).

Entrando en la problemática del mundo de la vida, Luhmann solía citar los §§. 7-9 de la "Introducción" de Erfahrung und Urteil. Veamos la particularidad de lo señalado en estos pasajes del texto tardío de Husserl en contraste con su planteo previo sobre la actitud natural.

Al respecto, si con Ideen I Husserl había hablado de la "tesis general de la actitud natural", ahora se presenta al mundo de la vida como "suelo universal de creencia pasiva en el ser" (Husserl, 1939: 24). Como se lee en Die Krisis, se trata de la "función-suelo" ["Boden»-Funktion] del mundo de la vida (Husserl, 1936: 158). Siguiendo al filósofo, "Podemos también decir que a toda actividad de conocimiento se anticipa un mundo particular como suelo universal, y esto quiere decir, antes que nada, un suelo universal de creencia pasiva en el ser que supone cada acción singular de conocimiento" (Husserl, 1939: 24-25, nuestra traducción).

Si en Ideen I Husserl aludió a la "proto-doxa", en su perspectiva tardía acerca de la mundanidad hizo referencia a la "doxa pasiva" (1939: 24).

El contraste entre ambos planteos puede aclararse de este modo: supongamos que dejando fuera de consideración a la temporalidad, fijamos la conciencia en una especie de "radiografía fenomenológica". Si tal cosa fuese posible nos encontraríamos la "osamenta" de la conciencia, la estructura intencional noético-noemática y, en este marco, al mundo constituido como correlato. Ahora tomemos en cuenta esta otra situación: nos despertamos y abrimos los ojos tras una noche de sueño. Sin más, el mundo está ahí. No tenemos que constituir la mundanidad cada vez que retornamos a la vigilia, hay una historia del sentido sedimentada, el mundo está siempre para nosotros ahí, ello no nos demanda labor alguna, tenemos el mundo dado de forma "pasiva" ${ }^{11}$

\footnotetext{
${ }^{11}$ Técnicamente descripto, estas dos formas de tratar el problema de la mundanidad refieren a una importante distinción que estableció Husserl entre fenomenología "estática" y "genética". Un aspecto central del análisis estático es que deja fuera de consideración al problema del
} 
A partir de ahí, Husserl sostuvo que el mundo es consustancial a su "función«suelo»". Esto quiere decir que las posibilidades a las que remite un objeto no son de cualquier índole, son remisiones a objetos "realmente" existentes.

En este terreno, puede entenderse la diferencia entre "posibilidades problemáticas" y "posibilidades abiertas" que recuperó Luhmann en su planteo. Pues en Erfahrung und Urteil se sostiene que la percepción puede desarrollarse continuamente o con obstrucciones, de este modo, "....en vez de la realización de las intenciones de expectativa se produce una decepción [Enttäuschung]" (1939: 94, nuestra traducción). Con ello surge lo "diverso" [anders] (ibid.: 97), el “...no así, más bien de otro modo" (ibid.: 95). Según Husserl, este es el origen de la negación pre-predicativa en la percepción. Se trata de un "tachar parcial" [partielle Durchstreichung] (ibid.: 98) el sentido de un objeto en el cual se mantiene intacto, sin embargo, un suelo de certeza de creencia en el sentido de este objeto $y$, ante todo, un suelo de creencia universal en el mundo. Pues si bien la realidad de cada objeto singular y sus determinaciones pueden trastabillar en el curso de la experiencia o en base a conocimientos científicos, la mismísima realidad del mundo de la vida como totalidad, es indudable para el hombre en su vida corriente, e igualmente, para aquel que hace ciencia. Este mundo está siempre dado de antemano, es decir, "pasivamente", en la forma de la certeza de realidad.

Otro tipo de modalización de la certeza primaria puede ocurrir cuando en vez del desplazamiento de una aprehensión de sentido por otra, se superponen dos aprehensiones de sentido. Se trata de una modalización de la certeza a la que Husserl aludió con el concepto de "posibilidades problemáticas" [problematische Möglichkeiten] o, lo que es lo mismo, "posibilidades

tiempo. En Ideen I Husserl no tomó en cuenta este tema incluso cuando esbozó una caracterización básica de la temporalidad. De este modo, aclaró que "Lo absoluto «trascendental» que hemos preparado por medio de las reducciones, en verdad no es lo último, es algo que se constituye a sí mismo en cierto sentido que yace profundamente y es completamente peculiar teniendo su fuente originaria en un absoluto último y verdadero" (Husserl, 1913: 182, nuestra traducción). El absoluto en cuestión es la "conciencia de tiempo" [Zeitbewusstsein] (ibid.). El hilo conductor del análisis de Ideen I puede caracterizarse mediante el primer punto del análisis estático que Husserl presentó en "El artículo de la Encycolpædia Britannica"; el análisis mencionado tiene como uno de sus pilares "...la descripción de las peculiaridades pertenecientes a la esencia de una vivencia intencional en general" (1928: 67). Este es el tipo de análisis que hemos mostrado al principio de la segunda parte de nuestro escrito. El análisis estático consiste en ofrecer un enfoque estructural, o formal general, de la vinculación de la conciencia con el mundo y sus objetos. En contraste, se puede señalar con Husserl que la fenomenología genética "...se ocupa de la génesis de la pasividad como primera génesis fundadora, en la cual el yo no participa como yo activo" (ibid.). El concepto de "pasividad" es un elemento distintivo del planteo genético. De ahí que el contraste entre fenomenología estática y fenomenología genética nos lleve a distinguir el planteo de la mundanidad de Ideen I y el de los escritos Die Krisis y Erfahrung und Urteil, en otros términos, el mundo como mero correlato y el mundo previamente dado de manera pasiva. En el análisis genético el tema del mundo tiene una importancia destacada. Por eso, Donn Welton (2003: 278) sostiene que en este tipo de análisis se enfatiza en el rol del "trasfondo" o "contexto". Con ello acuerda Klaus Held; con la fenomenología genética "La historia interna, o «génesis» donde la conciencia de horizonte se desarrolla y enriquece a sí misma, se transforma en [...] tema principal" (2003b: 53, subrayado en el original, nuestra traducción). 
cuestionables" [fragliche Möglichkeiten] (ibid.: 104). Aquí se halla el origen de la duda pre-predicativa que surge entre aprehensiones de sentido en conflicto.

La diferencia entre "posibilidades problemáticas" y "posibilidades abiertas" fue tratada por Husserl en el §. 21-c de Erfahrung und Urteil, parágrafo que Luhmann toma por referencia. De esta manera, en el transcurso normal de la percepción hay un horizonte de posibilidades abiertas, un "bosquejo" [Vorzeichnung] que tiene el mismo carácter de certeza que la conciencia actual. Sin embargo, este bosquejo señala posibilidades en una "generalidad indeterminada" [unbestimmte Allgemeinheit] (ibid.: 105-106). Por el contrario, en las posibilidades problemáticas se trata de posibilidades en conflicto o dudosas que tienen cada una un "peso" [Gewicht] que las establece como alternativas. En el caso de las posibilidades abiertas no hay un peso para las diferentes posibilidades, sino que, dentro del contexto del bosquejo que señala de un modo general lo que tiene que venir al caso bajo la forma de una certeza, están todas igualmente abiertas (ibid.: 107-108).

Pasemos a otro aspecto del concepto de horizonte. Concretamente, Husserl estableció una diferencia entre la conciencia de objetos y la conciencia de mundo: en tanto no hay mundanidad carente de objetos reales y, a la inversa, objetos reales sin mundo, la conciencia de existencia de este último es de una índole por completo sui generis. El mundo no está constituido al modo de un simple agregado de cosas, no es una suma de objetos, sino la unidad de un horizonte. Como pone de manifiesto Die Krisis, la realidad del mundo es la de la "unicidad" [Einzigkeit] para la cual el "plural" es carente de sentido (Husserl, 1936: 146).

En el §. 8 de Erfahrung und Urteil es enfocado otro problema que trató Luhmann en su crítica de la noción de mundo de Husserl: el tema de la "familiaridad" [Vertrautheit]. Como señaló el filósofo, "Nunca se efectúa una operación de conocimiento de objetos individuales de la experiencia, como si ellos estuvieran pre-dados por primera vez en tanto substratos aún enteramente indeterminados. El mundo es para nosotros siempre uno en el cual el conocimiento en las maneras más variadas ya ha hecho su obra..." (Husserl, 1939: 26, nuestra traducción).

De acuerdo con Husserl, una "estructura fundamental de la conciencia de mundo" es la estructura de lo "conocido" [Bekanntheit] y lo "desconocido" [Unbekanntheit] (ibid:: 33). Para caracterizar a esta estructura el filósofo se valió, justamente, del concepto de familiaridad. Con esto hizo referencia al conocimiento general del horizonte de mundo, el cual, en virtud de esta generalidad, no es conocido en sus particularidades individuales. Tal familiaridad general indeterminada se distribuye entre los objetos existentes y éstos adquieren una forma conocida, al interior de la cual, se realiza una nueva distribución de conocimiento/desconocimiento. Husserl expuso el tema de la familiaridad en base a su tratamiento del problema de las tipificaciones mencionado sin mayor despliegue en Ideen $I$.

Así, sostuvo que las posibilidades abiertas de un objeto están mentadas en una generalidad indeterminada. Esto vale para el "horizonte interno" de 
determinaciones de un objeto pero también para su "horizonte externo" de remisiones a otros objetos (1939: 28; 1936: 165). El horizonte externo que enmarca a todo objeto es el mundo de la vida.

A propósito, señaló el filósofo que el horizonte interno de un objeto se estructura por su "tipo a priori" de conocimiento amplio, pero estable, anterior a la especificación de la experiencia (Husserl, 1939: 32). A su vez, expuso que las experiencias potenciales de otro objetos del mundo se articulan en una típica a priori e invariable. Todas estas tipificaciones, en la perspectiva del autor, se conectan con una "típica de la totalidad" [Totalitätstypik] que corresponde al horizonte de mundo en conjunto (ibid.: 32). La familiaridad del mundo de la vida alude, por tanto, a esta articulación en diferentes niveles de tipificación apriorística de conocimiento y desconocimiento.

Respecto al §. 9 de Erfahrung und Urteil, Husserl mostró aquí la relación entre el juicio predicativo y la evidencia pre-predicativa de la experiencia. Aunque Luhmann hizo mención de este pasaje del texto, no contiene puntos destacados para un contraste con la teoría de sistemas sociales.

Lo tratado en esta parte de nuestro artículo se puede resumir según este conjunto de aspectos: Husserl expuso el tema del sentido en base a una filosofía de la subjetividad y la intersubjetividad; el método de su filosofía implica la reducción eidética, o variación eidética, y la reducción fenomenológica; el sentido es el estrato-núcleo del objeto intencional; la significación como concepto que se aplica al lenguaje se distingue de la noción más general de sentido; finalmente, el mundo se articula mediante la protodoxa o, de acuerdo al planteo husserliano tardío, la función-suelo del mundo de la vida.

\section{Balance crítico del nexo Luhmann-Husserl}

Habiendo mostrado las referencias de Luhmann al planteo de Husserl y la perspectiva fenomenológica sobre el sentido podemos especificar los puntos donde ambos autores han discrepado o coincidido. Hemos señalado al comienzo del artículo que las divergencias priman por sobre los encuentros entre la teoría de sistemas y la fenomenología. Hagamos entonces una revisión crítica del tándem Luhmann-Husserl.

Al respecto, señalamos que Luhmann desarrolló la cuestión del sentido en el marco de un enfoque funcionalista. A su vez, expusimos que la distinción entre hechos y esencias es parte central del método fenomenológico. A partir de ahí, aludimos a la reducción eidética y la variación eidética.

Justamente, uno de los aspectos que dejó de lado Luhmann es la reconducción de los hechos a las esencias. Con el funcionalismo como método comparativo, el sociólogo buscaba dar cuenta de las diversas posibilidades de estructuración de un sistema social en relación a la complejidad del mundo, pero ninguna de estas estructuras fue considerada por él como la "esencia" de un sistema. Toda estructura es "contingente". 
Este modo de proceder de las ciencias empíricas fue contemplado en el planteo de Husserl. Lo hemos detallado con el contraste entre los "universales empíricos" y los "universales puros". Así, mientras los conceptos obtenidos a través de comparaciones empíricas siempre están sujetos a revisión -de ahí su "accidentalidad"-, los universales de la fenomenología son a priori. Sobre esta base, puede observarse al método funcionalista como un instrumental de comparación de estructuras "contingentes" de sistemas empíricos, y a la variación eidética como proceso que recurre a la fantasía para elucidar el contenido "necesario" de un objeto.

En resumen, las comparaciones del funcionalismo y las variaciones fenomenológicas son tan opuestas como lo son la "contingencia" y la "necesidad".

En este respecto, expusimos que la distinción entre la esfera mundana y la trascendental es el otro aspecto básico del método husserliano. Tampoco siguió Luhmann al filósofo en este punto: explícitamente sostuvo que su "epojé" no ha de entenderse en sentido trascendental.

Ahora bien, ¿queda algo de la epojé sin los dos elementos principales del método de la fenomenología? Criticando el momento eidético y la perspectiva trascendental de la filosofía de Husserl aquello que parece haber rescatado Luhmann de la epojé es la ruptura de lo dado por sentado. Pero ¿hay que llamar epojé a este procedimiento? Consideramos que la fenomenología y la teoría de sistemas se rigen por principios opuestos. Esta es la perspectiva de Waldenfels, quien puso en contraste la noción de "fundamento" y la de "función". Citaremos al autor en extenso ya que presenta elocuentemente el punto que queremos señalar; de acuerdo con Waldenfels: "El concepto de fundamento pertenece al ámbito de la arquitectura. Aquí todo depende de que la construcción se erija sobre un suelo fijo y siga un lineamiento adecuado. (...) Por el contrario, el concepto de función se origina en el ámbito de las herramientas y la construcción de máquinas. Acá se espera que la herramienta en cuestión cumpla sus tareas, que la máquina opere correctamente, en breve: que algo, eventualmente alguien como funcionario, funcione por completo. Cuando consideramos a algo (o alguien) como funcional, entonces no lo entendemos como algo en sí mismo, sino como algo en relación con otra cosa, como también sabemos de las funciones matemáticas. Algo que funciona de un modo u otro, puede ser sustituido por otra cosa que funciona de la misma manera y alberga una «equivalencia funcional». En contraste, los fundamentos no pueden ser sustituidos sin que todo el edificio, también la edificación del mundo, se conmueva (Waldenfels, 2005: 56-57, nuestra traducción). Las discrepancias entre un enfoque funcionalista del sentido y uno fenomenológico responden a diferentes puntos de partida metodológicos.

A propósito, el enfoque de Luhmann revoca el estatuto de fundamento que en Husserl tienen la subjetividad y, en consecuencia, la intersubjetividad. La teoría de sistemas sociales críticó el vínculo que el filósofo estableció entre la subjetividad y el sentido $y$, sobre esta base, trasladó nociones que en la fenomenología fueron elaboradas para enfocar el ámbito de la conciencia, 
hacia un concepto general de sentido aplicable por igual a los sistemas psíquicos y sociales.

Ciertamente, esto se contradice con el objetivo principal de la teoría de sistemas sociales que fue definir la especificidad de lo social, pues ¿cómo mostrar tal especificidad si conceptos centrales para la perspectiva de sistemas sociales son tomados de un planteo acerca de la conciencia, la cual, desde las premisas propias de la teoría, constituye un sistema diferente a los sistemas sociales? ¿La diferencia operativa de estos sistemas no aporta nada a la definición del modo en que constituyen sentido? Por otra parte, ¿no conduce también esto al oscurecimiento de lo característico de la conciencia? No criticamos que tanto los sistemas sociales como los psíquicos sean "sistemas constitutivos de sentido", pero una teoría que ha buscado dar cuenta de la particularidad de lo social debería poder definir lo específico de la constitución social de sentido y, por añadidura, lo característico de la constitución de sentido que realiza la conciencia. La formula de la "reducción de la complejidad" no esclarece suficientemente la cuestión. Tanto los sistemas sociales como los sistemas psíquicos reducen complejidad por medio del sentido, sin embargo, ¿cómo lo hacen?

En lo que respecta a Husserl, la interpretación que Luhmann hizo del tema del sentido puede considerarse como una falacia de nivel: transportar de modo incólume a los sistemas sociales lo que fue definido para el terreno de la conciencia.

Una vez aceptada esta generalización al ámbito de lo social surgen otros problemas. Uno de ellos tiene que ver con la polaridad autorreferencia/heterorreferencia. En Husserl el sentido es el "estrato-núcleo" del objeto noemático. El filósofo ubicó al sentido del lado de la heterorreferencia de la conciencia. En contrapunto, el concepto de sentido de Luhmann enfatiza en el carácter autorreferencial de los sistemas psíquicos y sociales. El sentido es el reverso de la autopoiesis de estos sistemas. ${ }^{12}$

Asimismo, en sus escritos Luhmann abundó en alusiones donde expuso que el sentido consiste en la diferencia entre actualidad y potencialidad. De acuerdo con el autor, al tomar este aspecto del planteo de Husserl estaba realizando una "descripción fenomenológica" del sentido. Recién hemos explicitado las

\footnotetext{
${ }^{12}$ Decimos que se trata de un énfasis de la teoría de Luhmann. En efecto, el sociólogo sostuvo que toda autorreferencia es "autorreferencia concomitante" [mitlaufende Selbstreferenz] (Luhmann, 1984: 604). No hay autorreferencia pura. Con la autorreferencia siempre está implicada la heterorreferencia. Lo mismo ha de señalarse con respecto a Husserl. La noción de intencionalidad -el eje de su filosofía- muestra que la conciencia es heterorreferencial. Sin embargo, en los Manuskripte-C -por cierto, recientemente publicados-, Husserl insinuó que "Los actos del yo y el yo operante en ellos son siempre y necesariamente afectantes. Por tanto: necesidad de la autoafección" (2006, nuestra traducción). Reinterpretando las conocidas Vorlesungen de Husserl (1928) sobre la temporalidad en base a estos manuscritos, Dan Zahavi (2003) señaló que la autoafección es una forma de autoconciencia pre-reflexiva. Por tanto, en cada acto en que la conciencia intenciona un objeto, también se afecta a sí misma. De este modo, la conciencia es ineludiblemente autorreferencial y heterorreferencial. En suma, tanto Luhmann como Husserl incluyeron en sus teorías ambos polos de la distinción autorreferencia/heterorreferencia. Sin embargo, el primero enfatizó en la autorreferencialidad de los sistemas sociales y psíquicos, y el segundo en la heterorreferencialidad de la conciencia.
} 
diferencias entre el método de Husserl y el de Luhmann. Así, afirmamos que la teoría de sistemas sociales se apartó de la fenomenología tanto en el plano de la reducción eidética como en el terreno de la reducción fenomenológica: no hay ningún fundamento último de lo posible, todo fundamento puede ser disuelto a la luz de las "otras posibilidades". El principio del método luhmanniano no es la búsqueda del "fundamento" sino la ilustración de "funciones" en relación a las cuales las estructuras son intercambiables.

Este cuestionamiento metodológico se encuadra en los conceptos de complejidad y contingencia con los que Luhmann reelaboró el tema husserliano del horizonte y definió su noción de sentido. Como ya se indicó, la complejidad y la contingencia implican selectividad, es decir, "peligro de decepción". En contraste, como hemos visto con el tema de las posibilidades abiertas y las posibilidades problemáticas, Husserl dio cuenta de la posibilidad de decepción, pero, en un principio, señaló que lo potencial tiene el mismo valor de certeza y realidad que lo actual. En último término, lo que discute la teoría de sistemas sociales es la eficacia de la "proto-doxa" en la distinción actual/potencial. De ahí que para Luhmann estuviese incluido en el horizonte de potencialidad no sólo lo "real", sino también lo "condicionalmente real" y lo negativo o "irreal". En la fenomenología estas variaciones son vistas como "modalizaciones" de la "proto-doxa", pero la certeza de realidad, no la contingencia, tiene un lugar privilegiado y fundante en este planteo. A la par, no hay que dejar de tener en cuenta que en la actitud natural el hombre no se encuentra con meras cosas, el mundo inmediato es un mundo donde los objetos aparecen valorados y son utilizados.

Lo que Luhmann buscó enfocar es, por tanto, que en la apertura de lo posible, es decir, en las remisiones de sentido de toda actualidad, nunca está decidida de antemano la "realidad" del mundo. Esta interpretación es coherente con los conceptos de complejidad y contingencia. Ahora bien, se desprende de ahí un interrogante, a saber: ¿puede sostenerse una teoría sociológica empírica como pretendió ser la de Luhmann en base a un concepto de mundo que corre el riesgo de caer en lo "irreal"? ¿No necesita una teoría de este estilo, precisamente, un concepto de mundo "real"?

Otro tanto puede decirse de la crítica de Luhmann a la noción de mundo de la vida. Hemos mencionado que el sociólogo sostuvo que Husserl confunde "suelo" y "horizonte" en su planteo. Ahora bien, ¿qué puede ser un horizonte sin suelo? ¿No nos deja esto un concepto vacío de mundo? La crítica de Luhmann viene nuevamente por el lado de los conceptos de complejidad y contingencia. Para la teoría de sistemas sociales la mundanidad no puede ser un ámbito de objetividades pre-dadas. El mundo es un horizonte de "otras posibilidades" (Luhmann, 1971: 46) o de "acontecimientos posibles" (Luhmann, 1967a: 146). Por cierto, en todo momento el autor dejó ver que sentido y mundo son reverso uno del otro. Pero, en algunas ocasiones, separó sentido y mundo. De esta forma, las posibilidades que abarca el horizonte de la mundanidad fueron entendidas también como "alteración" [Störung] o "ruido" [Rauschen]: "Una preferencia por el sentido contra el mundo, por el orden contra la alteración, por la información contra el ruido, es sólo una preferencia. No hace a la contraparte prescindible” (Luhmann, 1984: 123). Así, “...los 
procesos de sentido viven de la alteración, se alimentan del desorden, se dejan llevar por el ruido..." (ibid.). En tanto "ruido" y "alteración", el mundo aparecería, entonces, como una totalidad inestructurada, es decir, como contingencia y complejidad exógenas al sentido. Más razones para no ver al mundo como ámbito de objetividades pre-dadas.

Por lo demás, Luhmann sostuvo que el horizonte de mundanidad no puede ser a la vez suelo porque en Husserl el mundo no es más que un "correlato de acto". Consideramos que lo que no tuvo en cuenta el autor es la diferencia entre Ideen I y textos como Die Krisis y Erfahrung und Urteil. Cuando Husserl enfocó el tema del mundo de la vida en sus últimos textos no consideró a la mundanidad como mero correlato sino como mundo pre-dado pasivamente, de ahí que pueda justificarse la unidad de suelo y horizonte en la noción de mundo de la vida. Esta diferencia entre el texto de 1913 y los escritos tardíos de Husserl no fue captada por Luhmann en su crítica.

Asimismo, sostuvo Luhmann que la amalgama de las nociones de horizonte y suelo en el concepto de mundo de la vida esconde un análisis de la distinción familiar/no-familiar. Tal apreciación no hace justicia a la fenomenología. Pues Husserl dio cuenta de lo familiar y no-familiar en su desarrollo del tema de las tipificaciones y el mundo de la vida. Todo conocimiento, implica, a su vez, un desconocimiento. Es una interpretación parcial de la fenomenología suponer que en el mundo de la vida hay certezas sin una dosis de ignorancia. Sólo a partir de tal interpretación sesgada pudo separar Luhmann mundo de la vida y mundo a secas.

Dicho esto, hay dos puntos donde el planteo de Luhmann y el de Husserl sobre el sentido se encuentran. En primer lugar, aunque concibieron a la mundanidad de modo diferente, para ambos autores el mundo es la unidad de un horizonte que no puede entenderse como una pluralidad de cosas -según Husserl- o posibilidades -de acuerdo con Luhmann-. En segundo lugar, tanto Luhmann como Husserl consideraron que el sentido y el lenguaje no son términos idénticos.

Brevemente, se constata que, en conjunto, el concepto de sentido de Luhmann y el de Husserl se desencuentran. Hay escasas conexiones para tender un puente entre ambas perspectivas. De ahí que resulte forzado ver en la teoría de sistemas sociales una auténtica "descripción fenomenológica" del sentido.

\section{Bibliografía}

(1996) CORSI, Giancarlo, ESPOSITO, Elena, BARALDI, Claudio, Glosario sobre la teoría de Niklas Luhmann, (Tr. Javier Torres Nafarrate, 1996), Ed. Anthropos, Barcelona.

(1972) ELEY, Lothar, Transzendentale Phänomenologie und Systemtheorie der Gesellschaft: Zur philosophischen Propädeutik der Sozialwissenschaften, Ed. Rombach, Friburgo. 
(2003a) HELD, Klaus, "Husserl's Phenomenological Method". En Donn Welton (Comp.), The New Husserl: A Critical Reader, Ed. Indiana University, Bloomington, pp 3-31.

(2003b) HELD, Klaus, "Husserl's Phenomenology of the Life-World". En Donn Welton (Comp.), The New Husserl: A Critical Reader, Ed. Indiana University, Bloomington, pp 32-62.

(1913) HUSSERL, Edmund, Ideen zu einer reinen Phänomenologie und phänomenologischen Philosophie. Erstes Buch: Allgemeine Einführung in die reine Phänomenologie (Husserliana III, 1950), Ed. Martinus Nijhoff, La Haya.

(1928) HUSSERL, Edmund, "El artículo de la Encycolpædia Britannica", (Tr. Antonio Zirión, 1990), Ed. UNAM, México.

(1931) HUSSERL, Edmund, Cartesianische Meditationen und Pariser Vorträge (Husserliana I, 1950), Ed. Martinus Nijhoff, La Haya.

(1936) HUSSERL, Edmund, Die Krisis der europäischen Wissenschaften und die transzendentale Phänomenologie (Husserliana VI, 1952), Ed. Martinus Nijhoff, La Haya.

(1939) HUSSERL, Edmund, Erfahrung und Urteil: Untersuchungen zur Genealogie der Logik, Ed. Academia, Praga.

(1966) HUSSERL, Edmund, "Vorlesungen zur Phänomenologie des inneren Zeitbewusstseins". En Edmund Husserl, Zur Phänomenologie des inneren Zeitbewusstseins.1893-1917 (Husserliana X, 1966), Ed. Martinus Nijhoff, La Haya, pp 4-131.

(2006) HUSSERL, Edmund, Späte Texte über die Zeitkonstitution. 1929-1934. Die C-Manuskripte, Ed. Springer, Dordrecht.

(1962) LUHMANN, Niklas, "Funktionale Methode und Systemtheorie". En Niklas Luhmann (Comp., 2009), Soziologische Aufklärung 1: Aufsätze zur Theorie sozialer Systeme, Ed. VS, Wiesbaden, pp 39-67.

(1967a) LUHMANN, Niklas, "Soziologie als Theorie sozialer Systeme". En Niklas Luhmann (Comp., 2009), Soziologische Aufklärung 1: Aufsätze zur Theorie sozialer Systeme, Ed. VS, Wiesbaden, pp 141-172.

(1967b) LUHMANN, Niklas, "Soziologische Aufklärung". En Niklas Luhmann (Comp., 2009) Soziologische Aufklärung 1: Aufsätze zur Theorie sozialer Systeme, Ed. VS, Wiesbaden, pp 81-115.

(1971) LUHMANN, Niklas, "Sinn als Grundbegriff der Soziologie". En Niklas Luhmann y Jürgen Habermas, Theorie der Gesellschaft oder Sozialtechnologie - Was leistet die Systemforschung?, Ed. Suhrkamp, Frankfurt, pp 25-100.

(1984) LUHMANN, Niklas, Soziale Systeme: Grundriß einer allgemeine Theorie, Ed. Suhrkamp, Frankfurt.

(1986a) LUHMANN, Niklas, "Die Lebenswelt - nach Rücksprache mit Phänomenologen". En Gerhard Preyer, Georg Peter y Alexander Ulfig (Comps.), Lebenswelt und System in Philosophie und Phänomenologie, Ed. Humanities Online, Frankfurt, pp 268-289.

(1986b) LUHMANN, Niklas, "Intersubjektivität oder Kommunikation: Unterschiedliche Ausgangspunkte soziologischer Theoriebildung". En Niklas Luhmann (Comp., 2008), Soziologische Aufklärung 6: Die Soziologie und der Mensch, Ed. VS, Wiesbaden, pp 162-179.

(1987a) LUHMANN, Niklas, Archimedes und wir, Ed. Merve, Berlín.

(1987b) LUHMANN, Niklas, "Was ist Kommunikation?". En Niklas Luhmann (Comp., 2008), Soziologische Aufklärung 6: Die Soziologie und der Mensch, Ed. VS, Wiesbaden, pp 109-120. 
(1987c) LUHMANN, Niklas, "Die Autopoiesis des Bewusstseins". En Niklas Luhmann (Comp., 2008), Soziologische Aufklärung 6: Die Soziologie und der Mensch, Ed. VS, Wiesbaden, pp 55-108.

(1992a) LUHMANN, Niklas, Introducción a la teoría de sistemas, (Tr. Javier Torres Nafarrate, 2007), Ed. Universidad Iberoamericana, México.

(1992b) LUHMANN, Niklas, Beobachtungen der Moderne, Ed. VS, Wiesbaden.

(1992c) LUHMANN, Niklas, "Die operative Geschlossenheit psychischer und sozialer Systeme". En Niklas Luhmann (Comp., 2008), Soziologische Aufklärung 6: Die Soziologie und der Mensch, Ed. VS, Wiesbaden, pp 26-37.

(1995) LUHMANN, Niklas, Die Kunst der Gesellschaft, Ed. Suhrkamp, Frankfurt.

(1996) LUHMANN, Niklas, Die neuzeitlichen Wissenschaften und die Phänomenologie, Ed. Picus, Viena.

(2009a) LUHMANN, Niklas, "Komplexität". En Niklas Luhmann (Comp., 2009), Soziologische Aufklärung 2: Aufsätze zur Theorie der Gesellschaft, Ed. VS, Wiesbaden, pp 255-276.

(2009b) LUHMANN, Niklas, "Haltlose Komplexität". En Niklas Luhmann (Comp., 2099), Soziologische Aufklärung 5: Konstruktivistische Perspektiven, Ed. VS, Wiesbaden, pp 58-74.

(2010) STICHWEH, Rudolf, "Niklas Luhmann", Pub. Electrónica, Universität Luzern,

Lucerna,

<http://www.unilu.ch/deu/prof._dr._rudolf_stichwehpublikationen_38043.html>

(2005) WALDENFELS, Bernhard, "Zwischen Fundamentalismus und Funktionalismus: Phänomenologie in krtischen Austausch mit den Human- und Sozialwissenschaften". En Helmutt Vetter (Comp.), Krise der Wissenschaft Wissenschaft der Krisis? Wiener Tagungen zur Phänomenologie, Ed. Östereichischer Gesellschaft für Phänomenologie, pp 56-68.

(2003) WELTON, Donn, "The Systematicity of Husserl's Transcendental Philosophy. From Static to Genetic Method". En Donn Welton (Comp.), The New Husserl: A Critical Reader, Ed. Indiana University, Bloomington, pp 255288.

(2003) ZAHAVI, Dan, "Inner Time-Consciousness and Pre-relfective Selfawareness". En Donn Welton, The New Husserl: A Critical Reader, Ed. Indian University, Bloomington, pp 157-180. 